\title{
Volume Replacement Therapy during Hip Arthroplasty using Hydroxyethyl Starch (130/0.4) Compared to Lactated Ringer Decreases Allogeneic Blood Transfusion and Postoperative Infection
}

\author{
Adilson Hamaji ${ }^{1}$, Ludhmila Hajjar* ${ }^{2}$, Marcelo Caiero ${ }^{3}$, Juliano Almeida ${ }^{4}$, \\ Rosana Ely Nakamura ${ }^{4}$, Eduardo A Osawa ${ }^{4}$, Julia Fukushima ${ }^{5}$, Filomena R Galas ${ }^{2}$, \\ Jose Otavio Costa Auler Junior ${ }^{6}$
}

1. Anesthesia Division, Instituto de Ortopedia e Traumatologia, Hospital das Clínicas da

Faculdade de Medicina da Universidade de São Paulo (HC-FMUSP), Brazil

2. PhD; Anesthesia Division, Heart Institute, HC-FM-USP, Brazil

3. Department of Orthopedic, FMUSP; Instituto de Ortopedia e Traumatologia, HC-FMUSP, Brazil

4. MD, Anesthesia Division, Cancer Institute, HC-FM-USP, Brazil

5. MSc; MD, Anesthesia Division, Heart Institute, HC-FM-USP, Brazil

6. PhD; Full Professor, Anesthesiology, HC-FM-USP, Brazil; Laboratory of Medical Investigation (LIM/08), FMUSP, Brazil Received from Hospital das Clinicas at the School of Medicine at the Universidade de Sao Paulo (HC-FM-USP), Brazil.

Submitted on August 18, 2011. Approved on March 15, 2012.

\section{Keywords:} Arthroplasty, Replacement, Hip; Anesthesia, Spinal; Blood Transfusion; Hetastarch; Hemodilution.

\begin{abstract}
Background and objectives: Hydroxyethyl starch (HES) 130/0.4 is considered an effective plasma expander when compared to crystalloids. There is controversy around its superiority regarding hemodynamic optimization and about possible detrimental effects on coagulation. The aim of this study was to compare the effects of HES 130/0.4 to lactated Ringer solution during hip arthroplasty in adult patients under spinal anesthesia regarding intraoperative bleeding, hemodynamic parameters, coagulation profile, transfusion requirements and clinical outcomes.

Methods: In this randomized, controlled trial, 48 patients scheduled for hip arthroplasty with spinal anesthesia were randomized into two groups: 24 patients were allocated to receive a preload

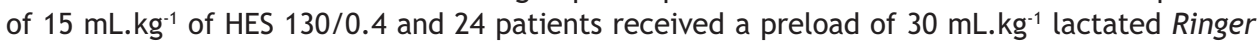
solution before surgery. Hemodynamic measurements, hemoglobin concentrations, biochemical parameters and coagulation tests were evaluated in three periods during surgical procedure. Patients received medical follow-up during their hospital stay and up to postoperative 30 days. Primary outcome was the requirement of red blood cell transfusion between groups during hospital stay. Secondary outcome were hemodynamic parameters, length of hospital stay, mortality and occurrence of clinical postoperative complications.
\end{abstract}

* Corresponding author: Av Dr Eneas C Aguiar no. 44 São Paulo, SP, Brazil Discipline of Anesthesiology, Instituto do Coração, Faculdade de Medicina da Universidade de São Paulo, Brazil

E-mail: pc.anestesiologia@incor.usp.br 
Results: Red blood cell transfusion was required in $17 \%$ of patients in the HES group and in $46 \%$ in the Ringer group $(p=.029)$. Postoperative infections were more frequently observed in the Ringer group (17\%) compared to the HES group $(0), p=.037$. There were no significant differences between groups in mortality, hospital length of stay and clinical complications other than infection.

Conclusions: During hip arthroplasty, patients treated with hypervolemic hemodilution with hydroxyethyl starch 130/0.4 required less transfusion and presented lower infection rate compared to patients who received lactated Ringer.

๑ 2013 Sociedade Brasileira de Anestesiologia. Published by Elsevier Editora Ltda. All rights reserved.

\section{Introduction}

The best type of fluid for intravascular volume replacement in major surgeries remains a matter of controversy ${ }^{1}$. Synthetic colloids seem to be more attractive because of their ability to maintain intravascular fluid volume and regional tissue perfusion more efficiently than crystalloids ${ }^{2-4}$. However, colloid solutions such as hydroxyethyl starchs (HES), gelatin and dextran, when compared to crystalloid solutions are more expensive and may be associated with adverse effects, such as acute renal failure, and platelet and coagulation disorders ${ }^{5,6}$.

Third-generation HES - as HES 130/0.4 and HES 130/0.42 - relate to less adverse effects ratio, probably due to structural moieties, as they present lower molecular weight and the degree of molar substitution, compared to other HES solutions ${ }^{7,8}$.

A multicenter randomized trial showed that allogenic transfusion increases morbidity and mortality rates in critically ill patients ${ }^{11}$. Adverse risks associated with blood transfusion include higher infection rates, immunologic risks and increase in costs ${ }^{12-15}$. Pharmacologic agents such as tranexamic acid or aminocaproic acid (EACA) could reduce perioperative blood loss by interfering with fibrinolysis ${ }^{16}$. Numerous small trials evaluated the use of antifibrinolytics in orthopedic surgery, observing their efficiency in reducing blood loss. Unfortunately, they were underpowered to detect efficacy on more relevant clinical outcomes. Furthermore, the remaining concern is that such agents may promote a hypercoagulable state within the context of high risk of venous thromboembolism, such as in orthopedic surgery ${ }^{17,18}$.

This prospective, randomized and controlled study was performed to compare the effects of HES 130/0.4 with lactated Ringer solution during hip arthroplasty in adult patients under spinal anesthesia regarding transfusion requirements, hemodynamic parameters and clinical postoperative complications.

\section{Methods}

\section{Study Design and Treatment Strategies}

We performed a prospective, randomized and controlled trial that enrolled consecutive patients scheduled for elective hip arthroplasty at the Instituto de Ortopedia e Traumatologia do Hospital das Clínicas da Universidade de São Paulo, Brazil, during a 24-month period. Patients were excluded for any of the following reasons: age younger than 18 years; obesity $\left(\mathrm{BMI}>40 \mathrm{~kg} \cdot \mathrm{m}^{-2}\right)$; chronic kidney disease (creatinine clearance lower than $60 \mathrm{~mL} \cdot \mathrm{min}^{-1} \cdot \mathrm{m}^{-2}$ ); American Society of Anesthesiologists (ASA) physical status classification III or higher; chronic anemia (preoperative hemoglobin lower than 10 g. $\mathrm{dL}^{-1}$ ); low platelet count (preoperative platelet count lower than $150 \times 10^{3} \cdot \mathrm{LL}^{-1}$ ); coagulopathy (previous history or prothrombin time longer than 14.8 seconds); left ventricular dysfunction (left ventricular ejection fraction lower than 40\%); myocardial infarction during the last 6 months, unstable angina, hepatic dysfunction (total bilirubin level higher than $\left.1.5 \mathrm{mg} . \mathrm{dL}^{-1}\right)$; and refusal to consent.

The study was approved by the Ethics Committee, Hospital das Clínicas, Universidade de São Paulo, and written informed consent was obtained from all patients before enrollment.

Patients were randomly assigned to the HES group or lactated Ringer group at a proportion of 1:1. Opaque envelopes arranged using a random-number table were prepared by the chief statistician and opened sequentially to determine the patient's treatment group. The research coordinator enrolled the participants and obtained informed consent. Information about the treatment was given to the anesthesiologist. Patients and the outcome assessors were blinded to group assignments.

Immediately after anesthetic procedure, patients assigned to the HES group received $15 \mathrm{~mL} \cdot \mathrm{kg}^{-1}$ intravenous of HES 6\% 130/0.4 and patients assigned to lactated Ringer group received $30 \mathrm{~mL} . \mathrm{kg}^{-1}$ intravenous of lactated Ringer. The trigger for additional fluid replacement was a systolic blood pressure lower than $90 \mathrm{~mm} \mathrm{Hg}$ and/or a decrease of $20 \%$ from baseline, or heart rate higher than 100 beats per minute. Vasopressors were used if there was persistent hypotension despite fluid replacement. Red blood cell transfusion was administered in patients with hemodynamic instability (mean arterial pressure lower than $65 \mathrm{~mm} \mathrm{Hg}$ despite of adequate fluid replenishment) associated with hemoglobin lower than $8 \mathrm{~g} \cdot \mathrm{dL}^{-1}$.

\section{Anesthesia protocol}

Patients were premedicated with $5 \mathrm{mg}$ of intravenous midazolam in the pre-induction anesthetic room. All patients were monitored with non-invasive blood pressure, continuous electrocardiography and pulse oximetry. A peripheral catheter $16 \mathrm{G}$ under local anesthesia was inserted in the cubital vein. Arterial and central venous catheters were placed as required. Lumbar spinal anesthesia, preferably into L3/L4 space with a $27 \mathrm{G}$ needle, was performed. A mixture of isobaric bupivacaine $20 \mathrm{mg}$ plus morphine $100 \mu \mathrm{g}$ was used in all patients. Sedation with intravenous propofol $0.1 \mu \mathrm{g} . \mathrm{kg}^{-1}$ was administered in all patients during the surgical procedure. Hypothermia was prevented during the surgery and recovery period with the use of a heating blanket and warmed intravenous fluids. After surgical procedure, all patients were transferred to post-anesthetic unit care until complete 
recovery from anesthesia. Patients were discharged from post-anesthetic unit to regular wards when they met AldreteKroulic discharge criteria.

\section{Baseline Assessment and Data Collection}

At the time of randomization, demographic and clinical data were obtained for each patient. Preoperative laboratory values collected up to 24 hours before surgery were recorded and included: hemoglobin, hematocrit, prothrombin time, active partial thromboplastin time, creatinine level, bilirubin level, and platelet count. During surgery, arterial pressure, heart rate and pulse oxymetry were recorded immediately before and after the regional anesthesia, every 15 minutes until the end of the surgery, as well as in the recovery room. Blood samples for measurement of hemoglobin levels, arterial blood gas analysis and assessment of coagulation and platelet aggregation were collected just before the surgery, 2 hours after the incision, at the end of the surgery and after 24 hours of the surgical procedure. Platelet aggregation was assessed by light transmission aggregometry using a PAP-4 aggregometer after ADP infusion ${ }^{19-20}$.

Blood losses from the surgical field were calculated by computing the amount of blood in surgical aspirators, and by weighing surgical sponges during the procedure. In the remaining 24 hours of the postoperative period, blood losses were considered by obtaining the volume from tube drainage. All administered intravenous fluids and red blood cells were recorded from the beginning of the surgery until the first 24 hours after the surgical procedure.

During patients' hospital stay, data were collected regarding the use of RBC transfusion and clinical complications. Clinical outcomes were evaluated in a blinded fashion.

Hematological complications were defined as impairment of platelet aggregation and increase in blood losses during perioperative and within the first 24 hours of postoperative period. Respiratory complications were defined as the need for mechanical ventilation and development of pneumonia or acute respiratory distress syndrome (ARDS) defined by standard criteria ${ }^{21}$. Cardiac complications included cardiogenic shock, tachyarrhythmia or perioperative cardiac ischemia ${ }^{22}$.

Renal function was evaluated daily using RIFLE (Renal risk, Injury, Failure, Loss of kidney function, End-stage kidney disease) classification ${ }^{23}$. The need for renal replacement therapy was recorded.

Infectious complications included: septic shock - defined by standard criteria); pneumonia - defined by a new lung infiltrate on chest radiography and the presence of at least two of the following criteria: temperature of $38^{\circ} \mathrm{C}$ or higher, leukocytosis greater than 12,000 cells. $\mu \mathrm{L}^{-1}$ or leucopenia lower than 3,000 cells. $\mu \mathrm{L}^{-1}$, or purulent endotracheal secretions with a Gram stain showing more than 25 neutrophils and fewer than 10 epithelial cells per field; wound infection - defined as a superficial or deep infection of the wound with positive findings on cultures obtained from the wound ${ }^{24}$.

\section{Outcome Measures}

The primary outcome was red blood transfusion requirement from operation time until 30 days after surgical procedure. Secondary outcomes included a comparison of hemodynamic variables and tissue perfusion parameters between groups during the surgical procedure, and postoperative incidence of all complications, including infectious, hematological, cardiovascular, respiratory and renal complications, and hospital length of stay.

\section{Statistical Analysis}

The sample size was calculated assuming a $40 \%$ incidence in transfusion requirement in crystalloid group. Considering an alpha error of 0.05 and a statistical power of 0.80 , we determined that a minimum of 23 patients in each group was necessary to conduct the present study.

Results are expressed as means with 95\% confidence intervals (Cls) or medians with interquartile ranges (IQR). Continuous variables were compared using a $t$ test or MannWhitney $U$ test and categorical variables using Pearson chi-square or Fisher's exact test. The differences between and within the groups were analyzed with one-way analysis of variance on ranks. Tests were 2-tailed, and values of $\mathrm{p}<0.05$ were considered statistically significant. Statistical analyses were performed using SPSS version 18.0 (SPSS Inc, Chicago, Illinois).

\section{Results}

A total of 48 patients were enrolled in the study: 24 assigned to the HES group 130/0.4 and 24 in the lactated Ringer group. Baseline characteristics were well matched between study groups (Table 1). Anesthetic requirements and duration of surgery were also similar in the groups. There was no difference regarding intraoperative body temperature and hemodynamic parameters - heart rate, systolic and diastolic pressures between groups (Table 2). No difference was found with regards to urinary output, need for norepinephrine, inotropic support and additional fluid administration.

Coagulation parameters, hemoglobin and hematocrit values at different times were similar in both groups (Table 3 ). The analysis of arterial blood gas did not reveal any difference between groups in values of arterial $\mathrm{pH}$, partial pressure of oxygen, partial pressure of carbon dioxide, base excess and bicarbonate (Table 4). Biochemical analysis was not different between groups (Table 5)

\section{Clinical Outcomes}

\section{Perioperative Blood Transfusion}

In the Ringer group, 11 patients (46\%) needed RBC transfusion during hospital stay compared to four patients (17\%) in the HES group $(p=0.029)$ (Figure 1$)$.

\section{Platelet Aggregation}

Platelet aggregation tests were significantly impaired in the HES group when compared to lactated Ringer group (Figure 2). $D$ = the difference between groups was demonstrated immediately after HES infusion ( $p=0.042$ ), after two hours $(p=0.029)$ and at the end of surgical procedure $(p=0.029)$. 
Table 1 Baseline Characteristics of Study Patients.

\begin{tabular}{llll}
\hline Variable & $\begin{array}{l}\text { HES 130 / 0.4 } \\
(\mathrm{N}=24)\end{array}$ & $\begin{array}{l}\text { Lactated Ringer } \\
(\mathrm{N}=24)\end{array}$ & $\mathrm{P}$ \\
\hline Age (years) - mean $(95 \% \mathrm{Cl})$ & $54(47$ to 61$)$ & $53(47$ to 59) & 0.889 \\
Male sex $-\mathrm{N}(\%)$ & $14(58.3 \%)$ & $9(37.5 \%)$ & 0.149 \\
Weight $(\mathrm{kg})-$ mean $(95 \% \mathrm{Cl})$ & $74(71$ to 77$)$ & $71(66$ to 75$)$ & 0.248 \\
Duration of surgery $(\mathrm{mim})-$ median (IQR) & $158(120$ to 190$)$ & $155(135$ to 180$)$ & 0.860 \\
Duration of anesthesia (min) - median (IQR) & $208(180$ to 240$)$ & 225 (169 to 240) & 0.615
\end{tabular}

$\mathrm{Cl}$ : Confidence Interval, IQR: Interquartile range.

Table 2 Hemodynamics and Clinical Variables of Patients Undergoing Hip Arthroplasty.

\begin{tabular}{|c|c|c|c|}
\hline Mean $(95 \% \mathrm{Cl})$ & $\begin{array}{l}\text { HES } 130 / 0.4 \\
(\mathrm{~N}=24)\end{array}$ & $\begin{array}{l}\text { Lactated Ringer } \\
(\mathrm{N}=24)\end{array}$ & $\mathrm{p}$ \\
\hline \multicolumn{4}{|l|}{ Heart Rate (bpm) } \\
\hline Baseline & 77 (74 to 81$)$ & 78 (73 to 83 ) & 0.058 \\
\hline $2 \mathrm{~h}$ after incision & 80 (76 to 85$)$ & 72 (67 to 77 ) & - \\
\hline End of surgery & 83 (79 to 87$)$ & 75 (70 to 80$)$ & - \\
\hline \multicolumn{4}{|c|}{$\begin{array}{l}\text { Systolic blood pressure }(\mathrm{mm} \\
\mathrm{Hg})\end{array}$} \\
\hline Baseline & 131 (124 to 138$)$ & 131 (126 to 137$)$ & 0.508 \\
\hline $2 \mathrm{~h}$ after incision* & 109 (102 to 115$)$ & 103 (98 to 108$)$ & - \\
\hline End of surgery* & 112 (107 to 118$)$ & 111 (107 to 115$)$ & - \\
\hline \multicolumn{4}{|c|}{$\begin{array}{l}\text { Dyastolic blood pressure }(\mathrm{mm} \\
\mathrm{Hg})\end{array}$} \\
\hline Baseline & 79 (75 to 83$)$ & 82 (77 to 87$)$ & 0.508 \\
\hline $2 \mathrm{~h}$ after incision* & 63 (59 to 67) & 57 (53 to 62) & - \\
\hline End of surgery* & 66 (63 to 69) & $66(61$ to 71$)$ & - \\
\hline \multicolumn{4}{|c|}{ Body temperature $\left({ }^{\circ} \mathrm{C}\right)$} \\
\hline Baseline & 36.3 (36.2 to 36.4$)$ & 36.3 (36.2 to 36.4$)$ & 0.508 \\
\hline $2 \mathrm{~h}$ after incision* & 36 (36 to 36.1 ) & 35.9 (35.8 to 36.1 ) & - \\
\hline End of surgery* & 36.2 (36.1 to 36.4 ) & 36.1 (35.9 to 36.2 ) & - \\
\hline
\end{tabular}

$\mathrm{Cl}$ : Confidence Interval; * significant difference with baseline.

\section{Perioperative Blood Loss}

The total amount of blood loss was significantly higher in HES group (mean $1.296 \mathrm{~mL} \pm 673.24$ in HES group versus $890.00 \pm$ $566.54 \mathrm{~mL}$ in lactated Ringer group; $\mathrm{p}<0.0460$ ) (Figure 3 ).

\section{Secondary Outcomes}

There were no significant differences between groups in hospital mortality or in length of stay either in the postanesthetic care unit or in regular wards (Table 6). There were no differences in the occurrence of cardiac complications, respiratory complications or renal complications. Patients treated with lactated Ringer had a higher number of infectious complications $(4 / 24,17 \%)$ than the HES group (0) $(p=0.03)$. Three patients presented wound infection and one patient had prosthesis infection. One postoperative death occurred in the HES group secondary to myocardial infarction leading to fatal cardiogenic shock.

\section{Discussion}

In patients undergoing hip arthroplasty, fluid replacement with hydroxyethyl starch $130 / 0.4$ resulted in higher rates of bleeding when compared to those that received lactated Ringer. Conversely, starch treated patients required less transfusion, and presented a lower rate of infection. The higher rates of bleeding attributed to the HES group did not compromise the clinical outcomes of these patients.

Elective major orthopedic surgery was chosen because it offers a common and standard surgical setting that allowed the study design to be largely based on clinical routine. The crystalloid-colloid volume ratio of 2:1 was established based on previous studies that compared the effectiveness of colloids against crystalloids ${ }^{18,25,26}$.

In our study, the higher impact of colloids on platelet aggregation tests did not seem to result in worse clinical outcomes, as the HES group received less transfusion. The 
Table 3 Hematological Analysis of Patients Undergoing Hip Arthroplasty.

\begin{tabular}{|c|c|c|c|}
\hline Mean $(95 \% \mathrm{Cl})$ & $\begin{array}{l}\text { HES } 130 / 0.4 \\
(\mathrm{~N}=24)\end{array}$ & $\begin{array}{l}\text { Lactated Ringer } \\
(\mathrm{N}=24)\end{array}$ & $\mathrm{p}$ \\
\hline \multicolumn{4}{|l|}{ Thrombin time (sec) } \\
\hline Baseline & 1.01 (0.98 to 1.04$)$ & 1.01 (0.98 to 1.03$)$ & 0.346 \\
\hline $2 \mathrm{~h}$ after incision* & $1.03(1$ to 1.06$)$ & $1.04(1.02$ to 1.06$)$ & - \\
\hline End of surgery* & 1.03 (1 to 1.07$)$ & 1.06 (1.04 to 1.09$)$ & - \\
\hline $24 \mathrm{~h}$ after surgery* & $1.02(0.99$ to 1.05$)$ & 1.04 (1 to 1.08$)$ & - \\
\hline \multicolumn{4}{|c|}{ Prothrombin time $(\mathrm{sec})^{*}$} \\
\hline Baseline & 1.03 (0.98 to 1.08$)$ & $1.43(0.62$ to 2.24$)$ & 0.597 \\
\hline $2 \mathrm{~h}$ after incision & 1.08 (1.03 to 1.12$)$ & 1.05 (1.02 to 1.08$)$ & - \\
\hline End of surgery & 1.18 (1.08 to 1.27$)$ & 1.12 (1.07 to 1.17$)$ & - \\
\hline $24 \mathrm{~h}$ after surgery & 1.21 (1.08 to 1.34$)$ & 1.12 (1.07 to 1.17$)$ & - \\
\hline \multicolumn{4}{|c|}{ Partial thromboplastin time (sec) } \\
\hline Baseline & 1.04 (1 to 1.09$)$ & $1.4(0.59$ to 2.21$)$ & 0.612 \\
\hline $2 \mathrm{~h}$ after incision & 1.09 (1.04 to 1.14$)$ & 1.02 (0.98 to 1.06$)$ & - \\
\hline End of surgery & $1.1(1.04$ to 1.16$)$ & 1.03 (0.99 to 1.07$)$ & - \\
\hline $24 \mathrm{~h}$ after surgery & $1.08(1.02$ to 1.15$)$ & 1.07 (1 to 1.15$)$ & - \\
\hline \multicolumn{4}{|l|}{ Hemoglobin (g/dL) } \\
\hline Baseline & $13.8(13.1$ to 14.5$)$ & $13.6(13$ to 14.3$)$ & 0.629 \\
\hline $2 \mathrm{~h}$ after incision* & $10.4(9.7$ to 11.2$)$ & 10.9 (10.1 to 11.7$)$ & - \\
\hline End of surgery* & $9.9(9.4$ to 10.3$)$ & $10.1(9.1$ to 11.2$)$ & - \\
\hline \multicolumn{4}{|l|}{ Hematocrit (\%) } \\
\hline Baseline & 42 (40 to 44 ) & 41 (39 to 43 ) & 0.772 \\
\hline $2 \mathrm{~h}$ after incision* & 31 (29 to 34$)$ & 32 (30 to 35$)$ & - \\
\hline End of surgery* & $30(28$ to 31$)$ & 30 (27 to 33$)$ & - \\
\hline
\end{tabular}

$\mathrm{Cl}$ : Confidence Interval; * significant difference with baseline.

hypothesis for this finding is that colloids accounted for improved hemodynamic stability; therefore, few patients in this group needed transfusion.

Considering the deleterious effects produced by allogeneic transfusion in different clinical scenarios ${ }^{27}$ and consistent data showing a relatively low impact of new generations of starch on coagulation ${ }^{28}$, HES administration would be an attractive alternative to traditional fluid replacement in major orthopedic surgeries under spinal anesthesia.

Traditional protocols involve fluid expansion with crystalloid and liberal protocol of allogeneic transfusion. In fact, evidence from previous studies showing benefits of allogeneic blood transfusion is deeply hindered by a significant number of underpowered studies with a small-sized population. In addition, the TRICC trial (Transfusion Requirements in Critical Care) - the only large RCT that compared a restrictive versus a liberal transfusion strategy - was sufficiently powered to favor a restrictive transfusional trigger in clinical ICU patients ${ }^{11}$. In a large orthopedic trial undertaken in 1999, a total of 2,640 hip and 1,305 knee arthroplasty patients were evaluated ${ }^{29}$. A total of $2,762(69 \%)$ received transfusion, of which only 35\% autologous and $25 \%$ allogeneic. The most important finding of this study was that the rate of wound infections was significantly higher (4.2\% vs. $1 \%)$ when comparing patients exposed to allogeneic and autologous transfusion, respectively ${ }^{29}$.

Nevertheless, common techniques that may reduce allogeneic blood transfusion during major surgeries - such as the acceptance of lower levels of hemoglobin before transfusion decision, routine use of acute normovolemic hemodilution $(\mathrm{ANH})$, cell salvage and pharmacological haemorrhage control - are not systematically used in most countries ${ }^{30,37}$. Although being extremely feasible, ANH is not largely employed. We have extensively investigated experimentally the effects of $\mathrm{ANH}$ on the heart ${ }^{31}$, lungs ${ }^{32}$ and different organs ${ }^{33}$. In these experimental studies, results favored colloid over crystalloid fluid replacement that concerns cellular and organ architecture preservation. In our study, however, patients submitted to hypervolemic hemodilution with starch $130 / 0.4$ presented more bleeding than those who received moderate quantities of lactated Ringer. This could be the result of hemodilution and/or direct action of starch on the coagulation system. 
Table 4 Gas Analysis of Patients Undergoing Hip Arthroplasty.

\begin{tabular}{|c|c|c|c|}
\hline Mean $(95 \% \mathrm{Cl})$ & $\begin{array}{l}\text { HES } 130 / 0.4 \\
(\mathrm{~N}=24)\end{array}$ & $\begin{array}{l}\text { Lactated Ringer } \\
(\mathrm{N}=24)\end{array}$ & $\mathrm{p}$ \\
\hline \multicolumn{4}{|l|}{$\mathrm{pH}$} \\
\hline Baseline & 7.37 (7.36 to 7.39$)$ & 7.38 (7.36 to 7.39$)$ & 0.240 \\
\hline $2 \mathrm{~h}$ after incision* & 7.37 (7.34 to 7.39$)$ & 7.32 (7.3 to 7.35$)$ & - \\
\hline End of surgery* & 7.33 (7.3 to 7.35$)$ & 7.33 (7.3 to 7.35$)$ & - \\
\hline $24 \mathrm{~h}$ after surgery & 7.37 (7.35 to 7.39$)$ & 7.36 (7.34 to 7.37$)$ & - \\
\hline \multicolumn{4}{|l|}{ Arterial $\mathrm{PO}_{2}(\mathrm{~mm} \mathrm{Hg})$} \\
\hline Baseline & 100 (84 to 117$)$ & 104 (90 to 119$)$ & 0.206 \\
\hline $2 \mathrm{~h}$ after incision* & $143(115$ to 171$)$ & 155 (136 to 174$)$ & - \\
\hline End of surgery* & 111 (97 to 125$)$ & 131 (112 to 151$)$ & - \\
\hline $24 \mathrm{~h}$ after surgery & 95 (93 to 97 ) & 99 (93 to 105$)$ & - \\
\hline \multicolumn{4}{|c|}{ Arterial $\mathrm{PCO}_{2}(\mathrm{~mm} \mathrm{Hg})$} \\
\hline Baseline & 41 (39 to 43 ) & 43 (38 to 47 ) & 0.742 \\
\hline $2 \mathrm{~h}$ after incision & 43 (40 to 45$)$ & 42 (39 to 45 ) & - \\
\hline End of surgery & 43 (41 to 46$)$ & 43 (41 to 46$)$ & - \\
\hline $24 \mathrm{~h}$ after surgery & 41 (39 to 42 ) & 41 (39 to 43 ) & - \\
\hline \multicolumn{4}{|c|}{ Base excess $\left(\mathrm{mmol}^{\mathrm{L}} \mathrm{L}^{-1}\right)$} \\
\hline Baseline & $-0.72(-1.37$ to -0.06$)$ & $-0.33(-1.31$ to 0.65$)$ & 0.894 \\
\hline $2 \mathrm{~h}$ after incision* & $-1.66(-2.61$ to -0.71$)$ & $-1.38(-2.47$ to -0.3$)$ & - \\
\hline End of surgery* & $-2.59(-3.71$ to -1.47$)$ & $-2.61(-3.66$ to -1.56$)$ & - \\
\hline $24 \mathrm{~h}$ after surgery & $-0.62(-1.36$ to 0.12$)$ & $-1(-1.68$ to -0.31$)$ & - \\
\hline \multicolumn{4}{|c|}{ Sodium bicarbonate (mEq. $\mathrm{L}^{-1}$ ) } \\
\hline Baseline & 24 (24 to 25$)$ & 24 (23 to 25$)$ & 0.577 \\
\hline $2 \mathrm{~h}$ after incision* & $23(22$ to 24$)$ & $23(22$ to 24$)$ & - \\
\hline End of surgery* & 23 (21 to 24$)$ & 22 (21 to 23$)$ & - \\
\hline $24 \mathrm{~h}$ after surgery & 24 (23 to 25$)$ & 24 (23 to 24$)$ & - \\
\hline
\end{tabular}

$\mathrm{Cl}$ : Confidence Interval; * significant difference with baseline.

Considering the effects of hemodilution, Ruttman and colleagues ${ }^{34}$ aimed to investigate whether hemodilution altered coagulation in patients scheduled to peripheral vascular surgery under regional anesthesia. Although much less volume was used in both groups compared to our study, the colloid group showed no coagulation disorder. In contrast, those who received more crystalloids presented more changes in the coagulation profile measured by thromboelastography. They concluded that this was caused by plasmatic dilution determined by rapid crystalloid infusion.

In our study, patients treated with starch showed more bleeding. This was possibly due to acute hemodilution, since $30 \mathrm{~mL} . \mathrm{kg}^{-1}$ was employed, in an attempt to maintain the patient hemodinamically stable without the need for further transfusion. The direct effects of starch on hemostasis and coagulation should also be considered. The platelet aggregation test used in our investigation was significantly affected and this finding stresses the more pronounced effects of starches on platelet function when compared to the effects on other components of the hemostatic system, as shown by several studies. Kozek-Langenecker et al. ${ }^{35}$ described the molecular mechanism of starches on the coagulation system. According to this study, the low-molar substitution is the main determinant of increased metabolic degradation, which ascertains undesirable effects, particularly on hemostasis. Slowly degradable HES, characterized by high- and mediummolecular weight, determine plasmatic reduction on the levels of factor VIII and VWF. At the same time, it decreases platelet reactivity under two mechanisms: decrease in the availability of the platelet fibrinogen receptor glycoprotein IIb-IIIa and interference on platelet-linking properties of vWF. On the other hand, fast degradable HES solutions with medium- and low-molecular weight showed reduced effects on hemostasis. 
Table 5 Biochemical Findings of Patients Undergoing Hip Arthroplasty.

\begin{tabular}{|c|c|c|c|}
\hline Mean $(95 \% \mathrm{Cl})$ & $\begin{array}{l}\text { HES } 130 / 0.4 \\
(\mathrm{~N}=24)\end{array}$ & $\begin{array}{l}\text { Lactated Ringer } \\
(\mathrm{N}=24)\end{array}$ & $\mathrm{p}$ \\
\hline \multicolumn{4}{|l|}{ Sodium (mEq. $\mathrm{L}^{-1}$ ) } \\
\hline Baseline & 141 (139 to 142$)$ & 139 (138 to 140$)$ & 0.055 \\
\hline $2 \mathrm{~h}$ after incision & 140 (139 to 141$)$ & 138 (137 to 139$)$ & - \\
\hline End of surgery & 139 (139 to 140$)$ & 139 (138 to 140$)$ & - \\
\hline $24 \mathrm{~h}$ after surgery & 139 (138 to 140$)$ & 138 (137 to 140$)$ & - \\
\hline \multicolumn{4}{|l|}{ Potassium (mEq. L-1) } \\
\hline Baseline & 4.2 (4 to 4.4$)$ & $4.2(4$ to 4.4$)$ & 0.746 \\
\hline $2 \mathrm{~h}$ after incision* & 3.9 (3.8 to 4.1$)$ & $4(3.8$ to 4.2$)$ & - \\
\hline End of surgery* & 3.9 (3.8 to 4$)$ & 3.9 (3.8 to 4$)$ & - \\
\hline $24 \mathrm{~h}$ after surgery* & 3.9 (3.7 to 4$)$ & 3.9 (3.8 to 4$)$ & - \\
\hline \multicolumn{4}{|l|}{ AST (U/L) } \\
\hline Baseline & 20.8 (17.3 to 24.4 ) & 19.1 (16.9 to 21.3$)$ & 0.162 \\
\hline $2 \mathrm{~h}$ after incision & 21.6 (18.7 to 24.5$)$ & 18.7 (16.7 to 20.7$)$ & - \\
\hline End of surgery & 21 (17.8 to 24.1$)$ & $18.9(17.1$ to 20.6$)$ & - \\
\hline $24 \mathrm{~h}$ after surgery & 22.3 (18.6 to 26$)$ & 18.5 (16.1 to 20.9$)$ & - \\
\hline \multicolumn{4}{|l|}{ ALT (U/L) } \\
\hline Baseline & $19.3(16.7$ to 21.9$)$ & 17.1 (14.2 to 20.1$)$ & 0.091 \\
\hline $2 \mathrm{~h}$ after incision & 19 (16.8 to 21.2 ) & $17(15$ to 18.9$)$ & - \\
\hline End of surgery & $19.3(17.1$ to 21.4$)$ & 16.7 (14.9 to 18.4$)$ & - \\
\hline $24 \mathrm{~h}$ after surgery & 20.5 (17.7 to 23.2$)$ & 16.8 (14.7 to 18.8$)$ & - \\
\hline \multicolumn{4}{|c|}{ Serum glucose $\left(\mathrm{mg} \cdot \mathrm{dL}^{-1}\right)$} \\
\hline Baseline & $93(87$ to 98$)$ & $96(91$ to 100$)$ & 0.617 \\
\hline $2 \mathrm{~h}$ after incision* & 102 (96 to 108$)$ & 100 (96 to 104$)$ & - \\
\hline End of surgery* & 104 (97 to 111$)$ & 100 (96 to 104$)$ & - \\
\hline $24 \mathrm{~h}$ after surgery* & 108 (99 to 118 ) & 105 (96 to 113 ) & - \\
\hline \multicolumn{4}{|c|}{ Serum creatinine $\left(\mathrm{mg} \cdot \mathrm{dL}^{-1}\right)$} \\
\hline Baseline & $0.86(0.77$ to 0.95$)$ & 0.82 (0.71 to 0.92$)$ & 0.336 \\
\hline $24 \mathrm{~h}$ after surgery* & 0.97 (0.88 to 1.05$)$ & 0.87 (0.75 to 0.99$)$ & - \\
\hline
\end{tabular}

$\mathrm{Cl}$ : Confidence Interval; * significant difference with baseline.

In this context, Gandhi et al. ${ }^{10}$ compared the safety of two starches (HES $130 / 0.4$ vs. HES 670/0.75 in saline) during major orthopedic surgery ${ }^{10}$. The primary safety endpoints were calculated: total erythrocyte loss, the nadir factor VIII activity, and the nadir von Willebrand factor concentration within 2 hours of surgery completion. The total volume of colloid solution required for intraoperative volume replacement did not differ between HES 130/0.4 and hetastarch. The nadir factor VIII activity within 2 hours of the end of surgery decreased in both groups, but was lower for hetastarch than for HES $130 / 0.4(p=.0499)$. For those who received more than 1,000 $\mathrm{mL}$ of colloid, von Willebrand factor levels also decreased in both groups within 2 hours of the end of surgery, but the concentration was lower for hetastarch than for HES $130 / 0.4$. They concluded that HES $130 / 0.4$ and hetastarch were equally effective as plasma volume expanders, with HES $130 / 0.4$ showing a lesser effect on coagulation ${ }^{10}$. Our study showed a similar finding of the low impact of HES 130/0.4 on coagulation tests, except for platelet aggregation.

The impact of blood transfusion on infection rates was determined by several studies ${ }^{11,29}$ that correlated immunological interplay between blood transfusion and infection. 
Table 6 Clinical Outcomes in Patients Undergoing Hip Arthroplasty.

\begin{tabular}{llll}
\hline Variable & $\begin{array}{l}\text { HES 130 / 0.4 } \\
(\mathrm{N}=24)\end{array}$ & $\begin{array}{l}\text { Lactated Ringer } \\
(\mathrm{N}=24)\end{array}$ & $\mathrm{P}$ \\
\hline Length of hospital stay (days) - median (IQR) & $5(3$ to 7$)$ & $5(4$ to 6) & 0.323 \\
Cardiovascular complication & $1 / 24(4 \%)$ & $0 / 24(0 \%)$ & 1.000 \\
Infection & $0 / 24(0 \%)$ & $4 / 24(17 \%)$ & 0.037 \\
Renal complication & $1 / 24(4 \%)$ & $0 / 24(0 \%)$ & 1.000 \\
Respiratory complication & $1 / 24(4 \%)$ & $0 / 24(0 \%)$ & 1.000 \\
Death & $1 / 24(4 \%)$ & $0 / 24(0 \%)$ & 1.000
\end{tabular}

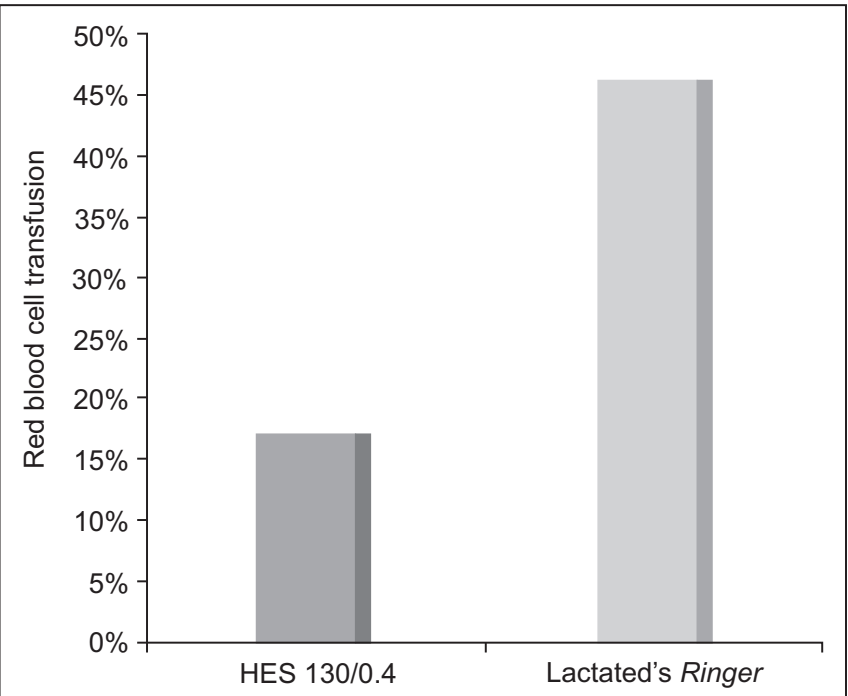

Figure 1 Relative Frequencies of Red Blood Cell Transfusion in Perioperative Period in Patients Undergoing Hip Arthroplasty.

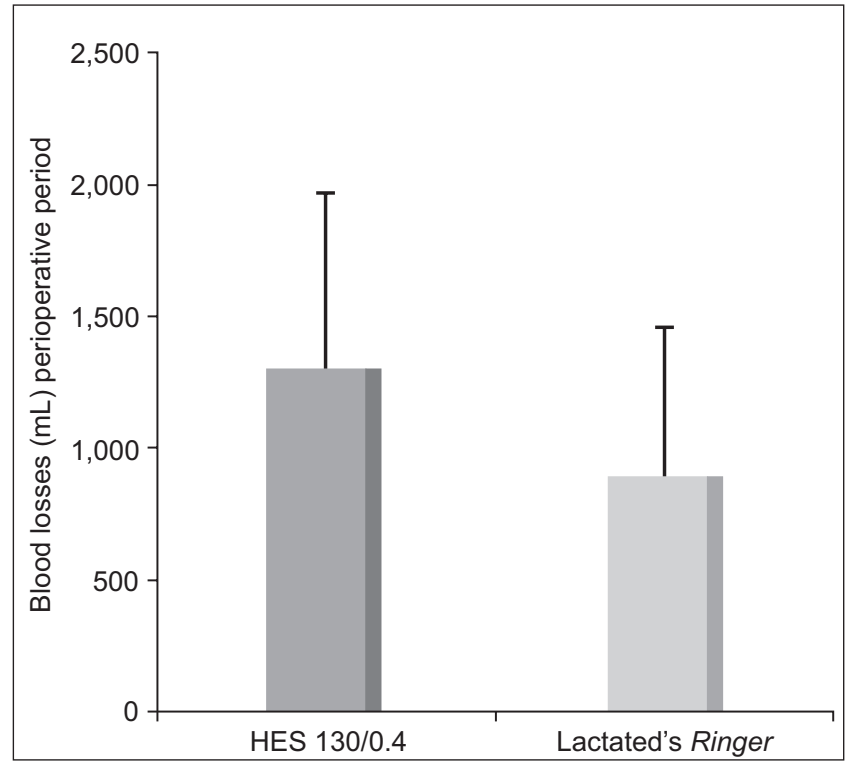

Figure 3 Platelet Aggregation After ADP Infusion in Patients Undergoing Hip Arthroplasty.

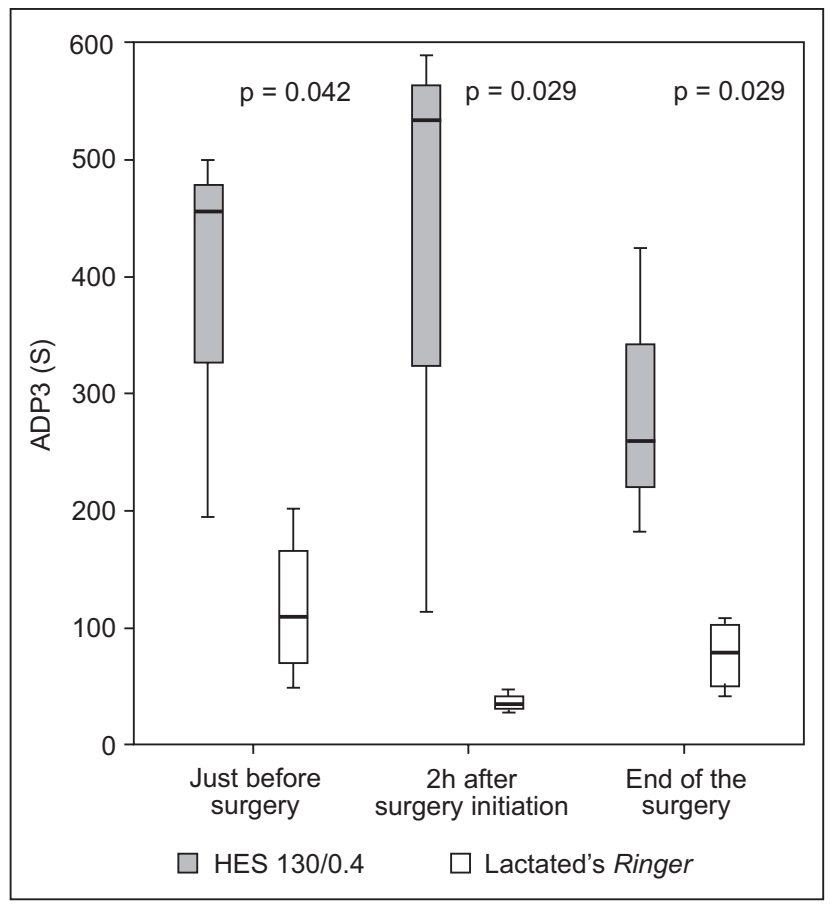

Figure 2 Blood Loss in Perioperative Period in Patients Undergoing Hip Arthroplasty.

In our study, the Ringer group required more transfusion and had a higher rate of infection. Four patients in this group had postoperative infection, and one of them was submitted to three surgical procedures combined with antibiotic therapy.

Fluid replacement with HES 130/0.4 resulted in reduced transfusion rates and in lower incidence of infection, compared to crystalloid solution, an outcome that suggests that colloid-induced hypervolemic hemodilution would be an attractive strategy to be applied in orthopedic surgery. 


\section{References}

1. Jones SB, Whitten CW, Despotis GJ, Monk TG - The influence of crystalloid and colloid replacement solutions in acute normovolemic hemodilution: a preliminary survey of hemostatic markers. Anesth Analg, 2003;96:363-368.

2. Lang K, Boldt J, Suttner S, Haisch G - Colloids versus crystalloids and tissue oxygen tension in patients undergoing major abdominal surgery. Anesth Analg, 2001;93:405-409.

3. Boldt J, Lehmann A, Römpert R, Haisch G, Isgro F - Volume therapy with a new hydroxyethyl starch solution in cardiac surgical patients before cardiopulmonary bypass. J Cardiothorac Vasc Anesth, 2000;14:264-268.

4. Karanko MS, Klossner JA, Laaksonen VO - Restoring volume by crystalloid versus colloid after coronary artery bypass: hemodynamics, lung water, oxygenation, and outcome. Crit Care Med, 1987; 15:559-566.

5. Boldt J, Knothe C, Zickmann B et al. - Influence of different intravascular volume therapies on platelet function in patients undergoing cardiopulmonary bypass. Anesth Analg, 1993;76:1185-1190.

6. Haisch G, Boldt J, Krebs C et al. - Influence of a new hydroxyethyl starch preparation (HES 130/0.4) on coagulation in cardiac surgical patients. J Cardiothorac Vasc Anesth, 2001;15:316321.

7. Gallandat RCG, Siemons AW, Baus D et al. - A novel hydroxyethyl starch (Voluven $®$ ) for effective perioperative plasma volume substitution in cardiac surgery. Can J Anesth, 2000;47:12071215.

8. Grauer MT, Baus D, Woessner R et al. - Effects on general safety and coagulation after long-term, high-dose volume therapy with $6 \%$ hydroxyethyl starch $130 / 0.4$ in patients with acute ischemic stroke. Results of a randomized, placebo-controlled, double-blind study. Critical Care, 2001;5:P115-S54.

9. Langeron O, Doelberg M, Ang ET, Bonnet F, Capdevila X, Coriat $P$ - Voluven $\circledast$ a lower substituted novel hydroxyethylstarch (HES $130 / 0.4$ ) causes fewer effects on coagulation in major orthopedic surgery than HES 200/0.5. Anesth Analg, 2001;92:855-862.

10. Gandhi SD, Weiskopf RB, Jungheinrich C et al. - Volume replacement therapy during major orthopedic surgery using Voluven ${ }^{\circledR}$ (hydroxyethyl starch $130 / 0.4$ ) or hetastarch. Anesthesiol, 2007;106:1120-1127.

11. Hébert PC, Wells G, Blajchman MA et al. - A multicenter, randomized, controlled clinical trial of transfusion requirements in critical care. Transfusion Requirements in Critical Care Investigators, Canadian Critical Care Trials Group. N Engl J Med, 1999;340:409-417.

12. Taylor RW, O’Brien JRN, Trottier Steven J et al. - Red blood cell transfusions and nosocomial infections in critically ill patients. Crit Care Med, 2006;34:2302-2308.

13. Hladik W, Dollard Sheila, Mermin J et al. - Transmission of Human Herpesvirus 8 by Blood Transfusion. New Engl J Med, 2006; 355:1331-1338.

14. Innerhofer P, Walleczek C, Luz G et al. - Transfusion of buffy coatdepleted blood components and risk of postoperative infection in orthopedic patients. Transfusion, 1999;39:625-632.

15. Spiess BD - Red cell transfusions and Guidelines: a work in progress. Hematol Oncol Clin North Am, 2007;21:185-200.

16. D’Ambrosio A, Borghi B, Damato A, D'Amato G, Antonacci D, Valeri $\mathrm{F}$ - Reducing perioperative blood loss in patients undergoing total hip arthroplasty. Int J Artif Organs, 1999;22:47-51.

17. Lentschener $\mathrm{C}$, Cottin $\mathrm{P}$, Bouaziz $\mathrm{H}$ et al. - Reduction of blood loss and transfusion requirement by aprotinin in posterior lumbar spine fusion. Anesth Analg, 1999;89:590-597.

18. Finfer S, Bellomo R, Boyce N, French J, Myburgh J, Norton R - A comparison of albumin and saline for fluid resuscitation in the intensive care unit. N Engl J Med, 2004;350:2247-2256.
19. Cardinal DC, Flower RJ - The electronic aggregometer: a novel device for assessing platelet behavior in blood. J Pharmacol Methods, 1980;3:135-158.

20. Bernard GR, Artigas A, Brigham KL et al. - The AmericanEuropean Consensus Conference on ARDS: definitions, mechanisms, relevant outcomes, and clinical trial coordination. AmJ Respir Crit Care Med, 1994;149:818-824.

21. Thygesen K, Alpert JS, White HD; Joint ESC/ACCF/AHA/WHF Task Force for the Redefinition of Myocardial Infarction Universal definition of myocardial infarction. J Am Coll Cardiol, 2007;50:2173-2195.

22. Haase M, Bellomo R, Matalanis G, Calzavacca P, Dragun D, HaaseFielitz A - A comparison of the RIFLE and Acute Kidney Injury Network classifications for cardiac surgery - associated acute kidney injury. J Thorac Cardiovasc Surg, 2009;138:1370-1376.

23. Despotis GJ, Skubas NJ, Goodnough LT - Optimal management of bleeding and transfusion in patients undergoing cardiac surgery. Semin Thorac Cardiovasc Surg, 1999;11:84-104.

24. Levy MM, Fink MP, Marshall JC et al.; SCCM/ESICM/ACCP/ATS/ SIS - $2001 \mathrm{SCCM} / E S I C M / A C C P / A T S / S I S$ International Sepsis Definitions Conference. Crit Care Med, 2003;31:1250-1256.

25. Riley E, Cohen S, Rubenstein, Flanagan B - Prevention of hypotension after spinal anesthesia for cesarean section: six percent hetastarch versus lactated Ringer's solution. Anesth Analg, 1995;81:838-842.

26. Hartog CS, Bauer M, Reinhart K - The efficacy and safety of colloid resuscitation in the critically ill. Anesth Analg, 2011;112:156-164.

27. Langdown AJ, Field J, Grote J, Himayat H - Aprotinin (Trasylol) does not reduce bleeding in primary total hip arthroplasty. J Arthroplasty, 2000;15:1009-1012.

28. Ellger B, Freyhoff J, van Aken H, Marcus MAE, Booke M - High dose volume replacement using HES 130/0.4 during major surgery does not alter coagulation. Europ J of Anaesth, 2002;19: 297.

29. Rosencher N, Kerkkamp HE, Macheras G et al. - Orthopedic Surgery Transfusion Hemoglobin European Overview (OSTHEO) study: blood management in elective knee and hip arthroplasty in Europe. Transfusion, 2003;43:459-469.

30. Holcomb JB - Methods for improved hemorrhage control. Crit Care, 2004;8:S57-S60.

31. Fraga A de O, Fantoni DT, Otsuki DA, Pasqualucci CA, Abduch MC, Auler Jr JOC - Evidence for myocardial defects under extreme acute normovolemic hemodilution with hydroxyethyl starch and lactated Ringer's solution. Shock, 2005;24:388-395.

32. Margarido CB, Margarido NF, Otsuki DA et al. - Pulmonary function is better preserved in pigs when acute normovolemic hemodilution is achieved with hydroxyethyl starch versus lactated Ringer's solution. Shock, 2007;27:390-396.

33. Otsuki DA, Fantoni DT, Margarido CB et al. - Hydroxyethyl starch is superior to lactated Ringer as a replacement fluid in a pig model of acute normovolaemic haemodilution. $\mathrm{Br} \mathrm{J}$ Anaesth, 2007; $98: 29-37$

34. Ruttmann TG, James MF, Finlayson J - Effects on coagulation of intravenous crystalloid or colloid in patients undergoing peripheral vascular surgery. $\mathrm{Br} J$ Anaesth, 2002;89:226-230.

35. Kozek-Langenecker S - In vitro testing of haemostatic sideeffects of colloids. Acta Anaesthesiol Scand, 2006;50:518.

36. Thyes C, Madjdpour C, Frascarolo P et al. - Effect of high- and low-molecular-weight low-substituted hydroxyethyl starch on blood coagulation during acute normovolemic hemodilution in pigs. Anesthesiol, 2006;105:1228-1237.

37. Davies L, Brown TJ, Haynes S, Payne K, Elliott RA, McCollum C - Cost-effectiveness of cell salvage and alternative methods of minimising perioperative allogeneic blood transfusion: a systematic review and economic model. Health Technol Assess, 2006;10:iii-iv, ix-x, 1-210. 